\title{
Potential to enhance the prescribing of generic drugs in patients with mental health problems in Austria; implications for the future
}

\author{
Brian Godman 1,2,3 *, Anna Bucsics, ${ }^{4}$,Thomas Burkhardt ${ }^{4}$, Jutta Piessnegger ${ }^{4}$, Manuela Schmitzer ${ }^{4}$, \\ Corrado Barbui ${ }^{5}$, Emanuel Raschi ${ }^{6}$, Marion Bennie ${ }^{78}$ and Lars L. Gustafsson ${ }^{1}$ \\ ${ }_{1}^{1}$ Division of Clinical Pharmacology, Karolinska University Hospital Huddinge, Stockholm, Sweden \\ ${ }^{2}$ Mario Negri Institute for Pharmacological Research, Milan, Italy \\ ${ }^{3}$ Prescribing Research Group, University of Liverpool Management School, Liverpool, UK \\ ${ }^{4}$ Hauptverband der Österreichischen Sozialversicherungsträger, Wien, Austria \\ ${ }^{5}$ Section of Psychiatry, Department of Public Health and Community Medicine, WHO Collaborating Centre for Research and Training in Mental Health and Service \\ Evaluation, University of Verona, Verona, Italy \\ ${ }^{6}$ Department of Medical and Surgical Sciences, Pharmacology Unit, Alma Mater Studiorum - University of Bologna, Bologna, Italy \\ 7 Strathclyde Institute for Pharmacy and Biomedical Sciences, University of Strathclyde, Glasgow, UK \\ ${ }^{8}$ Information Services Division, NHS National Services Scotland, Edinburgh, UK
}

Edited by:

Dominique J. Dubois, Université Libre de Bruxelles, Belgium

Reviewed by:

Jochen Fleischmann, Janssen

Germany, Germany

Suyash Prasad, BioMarin

Pharmaceutical, USA

Gerfried K. Nell, NPC Nell Pharma

Connect Ltd, Austria

${ }^{*}$ Correspondence:

Brian Godman, Division of Clinical

Pharmacology, Karolinska University

Hospital Huddinge, SE-141 86

Stockholm, Sweden.

e-mail: brian.godman@ki.se;

godman@marionegri.it
Background: Scrutiny over pharmaceutical expenditure is increasing leading to multiple reforms. This includes Austria with measures to lower generic prices and enhance their utilization. However the situation for newer antidepressants and atypical antipsychotic medicines (AAPs) is different to PPIs, statins, and renin-angiotensin inhibitor drugs with greater tailoring of therapy and no wish to switch products in stable patients. Authorities welcome generics though given the high costs particularly of single-sourced AAPs. Objective: Assess (a) changes in utilization of venlafaxine versus other newer antidepressants before and after availability of generics, (b) utilization of generic versus originator venlafaxine, (c) price reductions of venlafaxine over time and their influence on total expenditure, (d) utilization of risperidone versus other AAPs, (e) suggest potential additional reforms that could be introduced if pertinent to further enhance the use of generics. Methodology: A quasi-experimental study design with a segmented time series and an observational study. Utilization measured in defined daily doses (DDDs) and total expenditure per DDD and over time. Results: No appreciable changes in the utilization of venlafaxine and risperidone after generics. The reduction in expenditure/DDD for venlafaxine decreased overall expenditure on newer antidepressants by $5 \%$ by the end of the study versus just before generics despite a $37 \%$ increase in utilization. Expenditure will further decrease if reduced prescribing of duloxetine. Conclusion: Depression, schizophrenia, and bipolar diseases are complex diseases. As a result, specific measures are needed to encourage the prescribing of generic risperidone and venlafaxine when multiple choices are appropriate. Authorities cannot rely on a "Hawthorne" effect between classes to enhance the use of generics. Measures may include prescribing restrictions for duloxetine. No specific measures planned for AAPs with more multiple-sourced AAPs becoming available.

Keywords: Austria, antidepressants, atypical antipsychotics, drug utilization studies, generics, risperidone, reforms, schizophrenia

\section{BACKGROUND \\ GENERAL}

Scrutiny on pharmaceutical expenditure has intensified across Europe with its growth outstripping other components of ambulatory care, resulting in pharmaceutical expenditure becoming the largest or equaling the largest cost component in ambulatory care (Wettermark et al., 2008; Godman et al., 2008a, 2009a, 2010a, 2012a; Coma et al., 2009; Sermet et al., 2010; Voncina et al., 2011). This growth is set to continue unless addressed, driven by well known factors including changing demographics, rising patient expectations, strict clinical targets, and the continued launch of new premium priced medicines (Garattini et al., 2008; Wettermark et al., 2008; Godman et al., 2008a, 2009a, 2010a, 2012a; Coma et al., 2009; Sermet et al., 2010; Voncina et al., 2011).

These concerns have resulted in multiple reforms being instigated among countries to contain costs without compromising the quality of care (Godman et al., 2008a,b, 2009a,b, 2010b, 2011a,b, 2012b; Coma et al., 2009; Norman et al., 2009; Wettermark et al., 2009; McGinn et al., 2010; Sermet et al., 2010; Gustafsson et al., 2011; Voncina et al., 2011; Bennie et al., 2012). Austria is no exception. Multiple measures and initiatives introduced in Austria for existing medicines include pricing regulations for generics and 
originators once multiple-sourced products are available. Under these initiatives, the price of the third generic has to be at least $60 \%$ below single-sourced prices to be reimbursed (Godman et al., 2008a, 2009c, 2010a,c, 2011a). This price also establishes the reimbursed price for the originator (Godman et al., 2008a, 2009c, 2010a,c, 2011a). Thereafter, market forces act to obtain lower prices for successive branded generics. These include physician IT systems highlighting the cheapest multiple-sourced product, which build on quarterly information sent to physicians, physicians' prescribing costs benchmarked against each other coupled with financial incentives to prescribe the cheapest multiple-sourced product, as well as quality circles among physicians with the objective to increase the prescribing of generics versus originators (Godman et al., 2008a, 2009c, 2010a,c, 2012a; Spiegel et al., 2012).

These multiple measures helped increase prescribing efficiency in drug classes [Anatomical Therapeutic Chemical Classification ATC - Level 4; World Health Organization (WHO), 2003] where the products are seen as essentially similar in all or nearly all patients [Godman et al., 2008b, 2009a,c, 2010c, 2011a,b, 2012b; Voncina et al., 2011; McGinn et al., 2010; Gustafsson et al., 2011; Bennie et al., 2012]. Prescribing efficiency in this situation is defined as utilization growing at a faster rate than expenditure, with outcomes seen as similar between products. Pertinent drug classes include the proton pump inhibitors (PPIs), statins, and renin-angiotensin inhibitor drugs (Godman et al., 2009c, 2010c, 2011b, 2012b; Martikainen et al., 2010; McGinn et al., 2010; Gustafsson et al., 2011; Voncina et al., 2011; Bennie et al., 2012). The various measures, with their different intensities, resulted in the following outcomes in Austria (Godman et al., 2009c, 2010c, 2012b; Voncina et al., 2011):

- PPIs - utilization increased (Defined Daily Doses - DDDs) 3.6fold between 2001 and 2007 (DDDs) but total expenditure only increased 2.1-fold

- Statins - utilization increased approximately 2.4-fold (DDDs) between 2001 and 2007 but there was a 3\% decrease in total expenditure

- Angiotensin Converting Enzyme Inhibitors (ACEIs) and Angiotensin Receptor Blockers (ARBs) - utilization increased 69\% between 2001 and 2007, with total expenditure increasing only $23 \%$.

\section{ANTIDEPRESSANTS}

Newer antidepressants, including the dual acting antidepressants venlafaxine and mirtazapine, have also lost their patents during the past decade in Austria. Venlafaxine and mirtazapine are typically prescribed second line after the Selective Serotonin Re-uptake Inhibitors (SSRIs) with their increased effectiveness over the SSRIs (Yu-Isenberg et al., 2004; Baldomero et al., 2005; Agüera-Ortiz and Ramos Garcia, 2006; Cipriani et al., 2009). Among the newer antidepressants, duloxetine and reboxetine appear to be less effective than venlafaxine and mirtazapine (Cipriani et al., 2009).

Venlafaxine in Austria now includes generic immediate release (IR) and extended release (ER) formulations from May 2009. ER venlafaxine was launched to reduce possible side-effects associated with IR venlafaxine (Yu-Isenberg et al., 2004; Baldomero et al., 2005; Agüera-Ortiz and Ramos Garcia, 2006). Consequently, there should be an opportunity to save resources with the instigation of various measures to lower the prices of generics and the originator once multiple-sourced products become available as well as encourage their prescribing.

However unlike the PPIs, statins and renin-angiotensin inhibitor drugs, newer antidepressants should not be considered as a single class as there are differences between them both in terms of their effectiveness and side-effects (Cipriani et al., 2009). In view of this, it is acknowledged that patients should not be switched between therapies if they are responding to a particular antidepressant.

There is no reason though why patients should not be prescribed a multiple sourced antidepressant when suitable choices are available. This is especially the case when physicians are being encouraged through a variety of measures to preferentially prescribe generics (Godman et al., 2008a).

\section{ANTIPSYCHOTICS}

The utilization of atypical antipsychotic drugs has also been increasing in recent years for the management of schizophrenia and bipolar disorders (Knapp et al., 2005; Mirandola et al., 2006; NICE, 2008; Crystal et al., 2009; Wladysiuk et al., 2011). As a result of their increased prescribing, worldwide sales of atypical antipsychotic drugs were over \$US5bn per year in the early 2000s, reaching \$14.6bn in the US alone in 2009 (Andretta et al., 2005; Wladysiuk et al., 2011; Leslie and Rosenheck, 2012).

The increased prescribing of atypical antipsychotic medicines (AAPs) appears to have been driven by meta-analyses and other studies suggesting greater efficacy and functional recovery, as well as lower side-effects than typical antipsychotics and other drugs (Mond et al., 2003; Knapp et al., 2005; Leucht et al., 2009; Department of Justice settlement agreement, 2010; Alexander et al., 2011; Kishimoto et al., 2011; Fisk et al., 2012). These clinical improvements resulted in reports of improved compliance and persistence for atypical antipsychotics, although others have not seen this in practice (Taylor et al., 2003; Valenstein et al., 2004; Ren et al., 2006). As a result, in June 2002, the National Institute for Health and Clinical Excellence (NICE) in the UK recommended the use of atypical (newer) oral antipsychotic drugs in people with newly diagnosed schizophrenia and those currently taking typical (older) antipsychotics where their symptoms are being controlled but have problems with side-effects (Walley, 2004). NICE recently updated its guidance for patients with newly diagnosed schizophrenia offered oral antipsychotic medication (NICE, 2009), stating that healthcare professionals should "provide information and discuss the benefits and side-effect profile of each drug with the service user. The choice of drug should be made by the service user and healthcare professional together, considering:

- the relative potential of individual antipsychotic drugs to cause extrapyramidal side-effects (including akathisia), metabolic sideeffects (including weight gain), and other side-effects (including unpleasant subjective experiences)

- the views of the carer where the service user agrees."

However, there have been concerns about the quality of the evidence and the extent of the differences in daily practice with the effectiveness of typical versus atypical antipsychotics (Walley, 2004). There has also been growing criticism that high-potency 
haloperidol (typical antipsychotic) was used as a comparator in the studies with second generation (atypical antipsychotics) thereby biasing the results as likely to be associated with a high rate of extrapyramidal side-effects, and only a limited number of studies used medium-potency first generation (typical) antipsychotics as the comparator (Leucht et al., 2003; Tyrer and Kendall, 2009). Alongside this, greater levels of side-effects such as weight gain, hyperlipidemia, and Type 2 diabetes with atypical antipsychotics (Andretta et al., 2005; Gardner et al., 2005; NICE, 2009; Tyrer and Kendall, 2009; Wladysiuk et al., 2011). In addition, the risk of QT prolongation and subsequent arrhythmia-related events, i.e., Torsade de Pointes (TdP) and Sudden Cardiac Death, is increasingly seen as an important safety aspect to consider when atypical antipsychotic drugs are being prescribed (Titier et al., 2005; Haddad and Sharma, 2007). In the past, atypical antipsychotics have been perceived as generally having a favorable cardiac safety profile compared with typical antipsychotic drugs. However, these beliefs have been undermined by a recent cohort study finding a dosedependent increased risk of sudden cardiac deaths among current users of atypical antipsychotic drugs (Ray et al., 2009), further corroborated by different case series (Vieweg et al., 2009) as well as pharmacovigilance analyses (Poluzzi et al., 2009; Meyer-Massetti et al., 2011), showing similar reporting ratios between typical and atypical antipsychotic drugs in clinical practice. Tiihonen et al. (2009) have also raised concerns regarding the prescribing of quetiapine. In a recent study, the highest risk of mortality in patients with schizophrenia prescribed atypical antipsychotic drugs was with quetiapine, and the lowest was with clozapine. Haloperidol and risperidone had slightly lower adjusted hazard ratios than quetiapine (Tiihonen et al., 2009).

These debates have continued with the publication of the various findings from the Clinical Antipsychotic Trials of Intervention Effectiveness (CATIE) study in the US showing limited differences in effectiveness between the various antipsychotics, although this is not without criticism (Lieberman et al., 2005; Lieberman and Stroup, 2011; Wladysiuk et al., 2011; Berkowitz et al., 2012). The studies do show though that the variation in the effectiveness of the different AAPs can be substantial between individual patients, and that side-effects can also differ between different AAPs (Lieberman and Stroup, 2011). Consequently, "treatments for schizophrenia must be individualized" (Lieberman and Stroup, 2011). These findings are endorsed by Cochrane Collaboration reviews and other studies suggesting tentatively that olanzapine may be somewhat more efficacious than some other second generation antipsychotic drugs although concerns with high drop-out rates in the studies, with mixed results with risperidone (Hargreaves and Gibson, 2005; Heres et al., 2006; Komossa et al., 2010, 2011).

Other authors believed the modest gains with atypical antipsychotic drugs that have reported do not adequately reflect the improvements in quality of life perceived by patients, clinicians, or carers (Magnus et al., 2005), leading to increased use. Consequently, it is likely there will continue to be growing utilization of atypical antipsychotic medicines (Knapp et al., 2005; Mirandola et al., 2006; NICE, 2008; Crystal et al., 2009; Wladysiuk et al., 2011).

As a result, the availability of generic atypical antipsychotic medicines at low prices should be welcomed by health authorities and health insurance agencies with growing resource pressures. The first atypical antipsychotic drug to become available among Western countries was clozapine, with published studies showing no difference in outcomes between the originator and generics in practice once the bioavailability problem with the first generic clozapine in the US had been resolved (Bazire and Burton, 2004; Healy et al., 2005; Alessi-Severini et al., 2006; Paton, 2006; Araszkiewicz et al., 2008). More recently, generic olanzapine and generic risperidone became available among European countries. Again, there appears to be no patient issues in practice (Araszkiewicz et al., 2008; Khorana et al., 2011; Wladysiuk et al., 2011; Correl and Carbon, 2012), although some authors are more cautious (Desmarais et al., 2011; Correl and Carbon, 2012).

However, it is recognized that schizophrenia and other conditions such as bipolar disorders are complex diseases to treat. In addition, atypical antipsychotic drugs should not be considered as one class (Heres et al., 2006; NICE, 2009; Lieberman and Stroup, 2011). As a result, greater necessity for tailoring treatments depending on the patient and their characteristics, including current co-morbidities, having considered the safety profile of each drug including its pharmacokinetic profile (NICE, 2009; Poluzzi et al., 2009; Ray et al., 2009; Tiihonen et al., 2009; Vieweg et al., 2009; Lieberman and Stroup, 2011; Meyer-Massetti et al., 2011). In addition, switching patients between treatments should never be considered if they are stable on a particular atypical antipsychotic drug.

\section{OBJECTIVES}

The availability of oral generic newer antidepressants as well as atypical antipsychotic drugs in addition to clozapine should in theory lead to their increased prescribing. However, this remains to be seen due to the complexities of treating depression, schizophrenia, and other mental health conditions compared with treating stomach related acid disorders, hypercholesterolemia or hypertension.

Consequently, the objectives of this paper are to assess (a) changes in the utilization of venlafaxine versus other newer antidepressants before and after the availability of generic IR and ER formulations, (b) utilization of generic versus originator venlafaxine, (c) price reductions of venlafaxine IR and ER over time and the subsequent influence on total expenditure of antidepressants over time, (d) the utilization of risperidone versus other atypical antipsychotic drugs over time following generic availability, (e) suggest potential additional reforms if pertinent that could be introduced in Austria to further enhance the prescribing of multiple-sourced antidepressants and atypical antipsychotic drugs when multiple drug choices are available and appropriate.

\section{METHODOLOGY}

Two methodologies were utilized. The first involves a quasiexperimental study design with a segmented time series (Grimshaw et al., 2000; Wagner et al., 2002) to analyze retrospectively monthly reimbursed prescriptions for all patients in Austria covered by the social health insurance system prescribed at least one newer antidepressant including mirtazapine (N06AX11), venlafaxine (N06AX16), reboxetine (N06AX18); duloxetine (N06AX21) and agomelatine [N06AX22; World Health 
Organization (WHO), 2012] from May 2007, i.e., 24 months before the availability of generic venlafaxine in May 2009 (IR and ER) to August 2011, 27 months after generic venlafaxine. Desvenlafaxine (N06AX23) was never reimbursed in Austria. The data source was the internal data warehouse of the HVB (BIG), Cube HMSTAT, based on the "maschinelle Heilmittelabrechnung," which covers approximately $98 \%$ of the Austrian population (Godman et al., 2009c, 2010c).

The second study is a retrospective observational study of the same population dispensed at least one atypical antipsychotic drug [N05AH03-05, N05AL05, N05AX08, 11-13; World Health Organization (WHO), 2003] between 2005, i.e., 1 year after generic risperidone became available, to 2010,6 years after generic risperidone became available. Clozapine was not included in the analysis as it is reserved for resistant patients due to its side-effect profile (Healy et al., 2005; Paton, 2006; Leucht et al., 2009, 2011; Asenjo Lobos et al., 2010; Raja, 2011; Wladysiuk et al., 2011). The data source was again the internal data warehouse of the HVB (BIG), Cube HMSTAT, based on the "maschinelle Heilmittelabrechnung," which covers approximately $98 \%$ of the Austrian population (Godman et al., 2009c, 2010c). No analysis of expenditure was undertaken as generic risperidone was already available by 2005 and reduced expenditure for risperidone is guaranteed given the current strict regulations governing the prices of generics and originators in Austria once multiple sourced products become available (Godman et al., 2008a, 2009c, 2010a,c, 2011a, 2012a).

The two methodologies were chosen to provide different data sets, especially since generic risperidone was already available before the study period.

Utilization was collated in terms of DDDs, with DDDs defined as "the average maintenance dose of a drug when used in its major indication in adults," as this measure is recognized as the international standard to assess utilization patterns within and between countries [World Health Organization (WHO), 2012]. 2011 DDDs were used in line with international guidance [Vlahovic-Palcevski et al., 2010; Godman et al., 2010b, 2011a; World Health Organization (WHO), 2003, 2012].

The regression analysis for the newer antidepressants was undertaken using the "R" methodology (R Core Team, 2012). Using this methodology, reimbursed prescriptions were explained by a variable "Time" with its origin in May 2009 (generic venlafaxine) and a variable "Inter" to model the change in slope following the availability of generic venlafaxine.

Total costs in Euros were again used for the analysis to facilitate comparisons with previous studies (Godman et al., 2009c, 2010c). This is because it is difficult in practice to disaggregate pharmacy and wholesaler mark-ups from total costs in Austria, compounded by $20-25 \%$ of the Austrian population currently exempt from basic co-payment. As a result, total costs provide a more robust measure than estimating reimbursed costs using any derived formula (Godman et al., 2009c, 2010c). Total costs are the price paid to the pharmacy for the product including the ex-factory price, the wholesaler, and pharmacy mark-ups but excluding VAT (Godman et al., 2009c, 2010c). Total expenditure per DDD was computed for generic and originator IR and ER venlafaxine, as well as total monthly expenditure of the newer antidepressants over time.
There has been no allowance for inflation as we wanted to compute the actual influence of the various policies on total expenditure, as well as total expenditure/DDD, over time for the various antidepressants. In addition, the tendency of authorities across Europe is to cut prices of both patented (single-sourced) drugs and generics when pharmaceutical expenditure is rising more rapidly than target budgets (Coma et al., 2009; Sermet et al., 2010; Godman et al., 2010b, 2011a; Garuoliene et al., 2011; Vogler et al., 2011; Voncina et al., 2011). Alongside this, a number of European countries establish their initial prices for generics based on originator pre-patent loss prices, i.e. singles-sourced prices, which includes Austria (Godman et al., 2008a, 2009c, 2010a,c, 2011a,b, 2012a,c; Voncina et al., 2011). Consequently the use of total expenditure, as well as no allowance for inflation, is in line with previous publications.

\section{RESULTS}

The utilization of newer antidepressants increased by $37 \%$ from the launch of generic venlafaxine (IR and ER) until the end of the study based on accumulated six monthly DDDs (Table 1).

This growth included increasing utilization of venlafaxine (Figure 1), although there was no change in the overall utilization pattern of venlafaxine before and after the availability of generic IR and ER venlafaxine (Figure 1) with a probability of 0.591 . This growth in the utilization of newer antidepressants (Table 1) is principally driven by increasing use of duloxetine in recent years, with the utilization of both reboxetine and agomelatine remaining low throughout the study period (Figure 1). As a result, the utilization of venlafaxine as a \% of total antidepressant utilization decreased from $46 \%$ of all DDDs just before generic ER venlafaxine to $44 \%$ by August 2011.

The increase in the utilization of the other antidepressants combined was significant at the 0.1 level $(p=0.0843)$, but not at the 0.05 level (Figure 1, Table 2).

There was a $5 \%$ reduction in total expenditure of the newer antidepressants 27 months after the availability of generic IR and ER venlafaxine at $€ 12.1 \mathrm{mn}$ (accumulated 6 months) versus $€ 12.725 \mathrm{mn}$ just before generic venlafaxine (accumulated 6 month basis). This was helped by a reduction in expenditure for venlafaxine after generic availability (Figure 2).

Table 1 | Utilization of newer antidepressants (mn DDDs) on an accumulated six monthly basis before and after the availability of generic venlafaxine ER (May 2009).

Months after generic venlafaxine

Six monthly accumulated data (DDDs mn)

18 months before 11,752

12 months before 12,701

6 months before

13,379

Launch generic venlafaxine

14,751

6 months after

15,804

12 months after

17,279

18 months after

18,120

24 months after

19,601

27 months after 


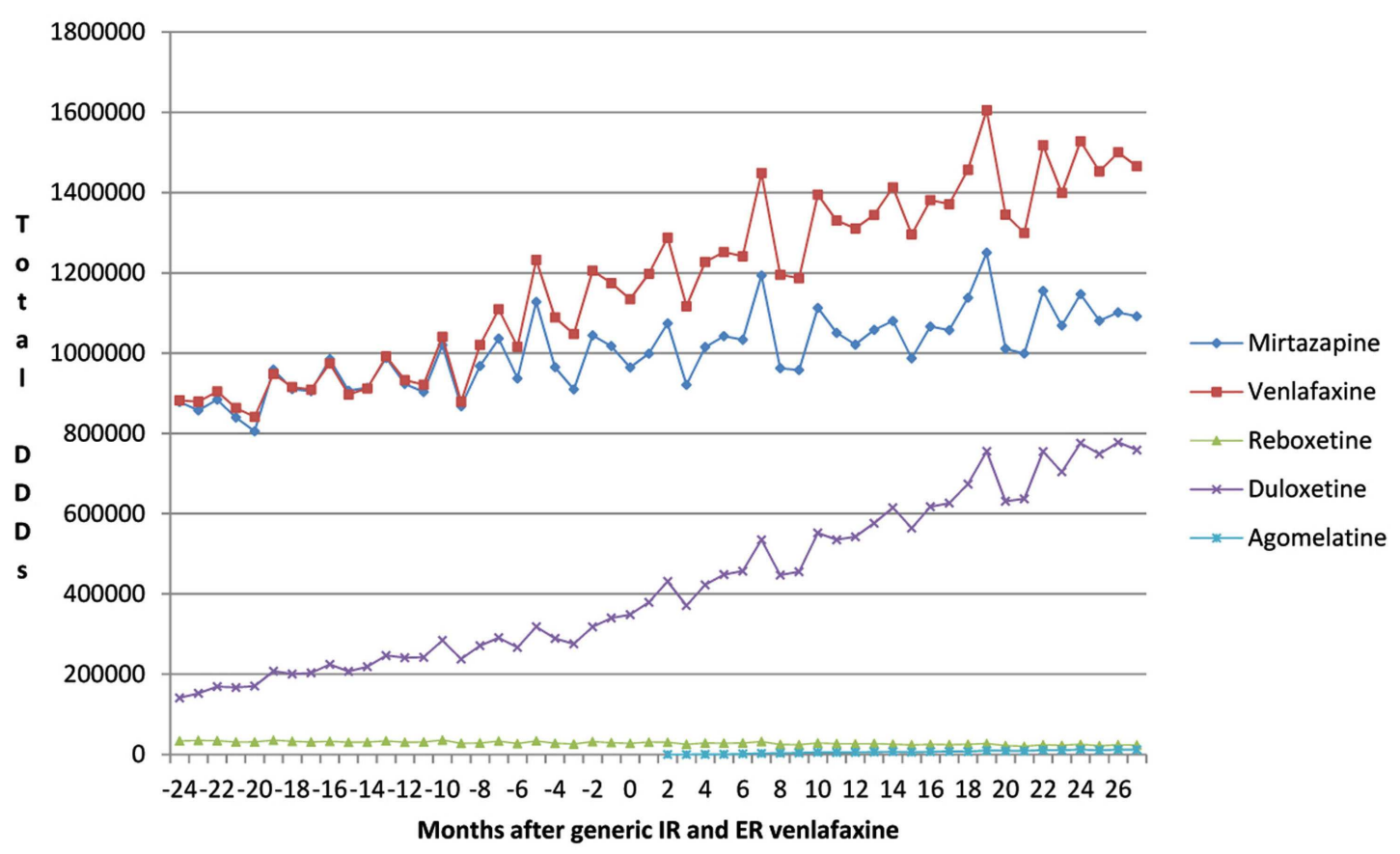

FIGURE 1 | Utilization pattern of newer antidepressants in DDDs before and after generic IR and ER venlafaxine (May 2009).

Table 2 | Residuals and coefficients for the change in the utilization of other antidepressants before and after generic ER venlafaxine.

\begin{tabular}{lllll}
\hline RESIDUALS & First Qtr & Median & Third Qtr \\
Minimum & -52437 & -4846 & 54932 & Maximum \\
-153307 & Estimate & Standard error & T value & 264627 \\
Coefficients & 1386886 & 26892 & 51.572 & Significance \\
Intercept & 14276 & 2125 & 6.719 & $<0.001$ \\
Time & 6010 & 3411 & 1.762 & $<0.001$ \\
Inter & & & 0.0843 \\
\hline
\end{tabular}

Residual standard error: 91070 on 49 degrees of freedom. Multiple R-squared: 0.901, Adjusted R-squared: 0.897. F-statistic: 223.1 on 2 and 49 DF. p-Value < 2.2e - 16.

The reduction in expenditure for venlafaxine was helped by a reduction in expenditure/DDD for both IR and ER venlafaxine once generics became available (Figure 3). Total expenditure/DDD for generic IR venlafaxine in August 2011 was $68 \%$ below single-sourced prices (Figure 3), with a similar reduction in the price of the originator. There was a lower reduction in expenditure/DDD for generic ER venlafaxine ER (42\% reduction) from May 2009 to August 2011.

There was increased utilization of risperidone after the availability of generic risperidone (Figure 4). However, the $81 \%$ growth in overall atypical antipsychotic utilization from 2005 to 2010 (DDD basis) was principally driven by increasing utilization of quetiapine and aripiprazole (Figure 4). This resulted in the utilization of risperidone as a percentage of total atypical antipsychotic DDDs decreasing from 32\% in 2005 to $24 \%$ in 2010.

\section{DISCUSSION AND CONCLUSION}

We believe the lack of change in the utilization pattern of venlafaxine after the availability of generic IR and ER venlafaxine
(Figure 1) reflects the greater complexity in treating patients with depression than those with stomach acid related disorders, hypercholesterolemia or hypertension with PPIs, statins, and renin-angiotensin inhibitor drugs respectively (Godman et al., 2009c, 2010c). Consequently, specific measures will be required to encourage the prescribing of multiple-sourced antidepressants when options are available to the prescribing physician. A similar situation is seen in the management of Parkinson's disease where patients require add-on therapies to prolong the effectiveness and compliance with their treatment (Brkicic et al., 2012). As a result, there is again a need for specific demand-side measures to change subsequent prescribing habits with greater individualization of treatment (Brkicic et al., 2012). Consequently, authorities cannot rely on a Hawthorne effect between classes (Holden, 2001; Verstappen et al., 2004; Trietsch et al., 2009; Konstantinou, 2012) especially for complex disease areas. The Hawthorne effect in studies relates to the confounding that occurs if experimenters fail to realize how the consequences of a given subject's performance in one area may affect activities in another area (Parsons, 1974). 


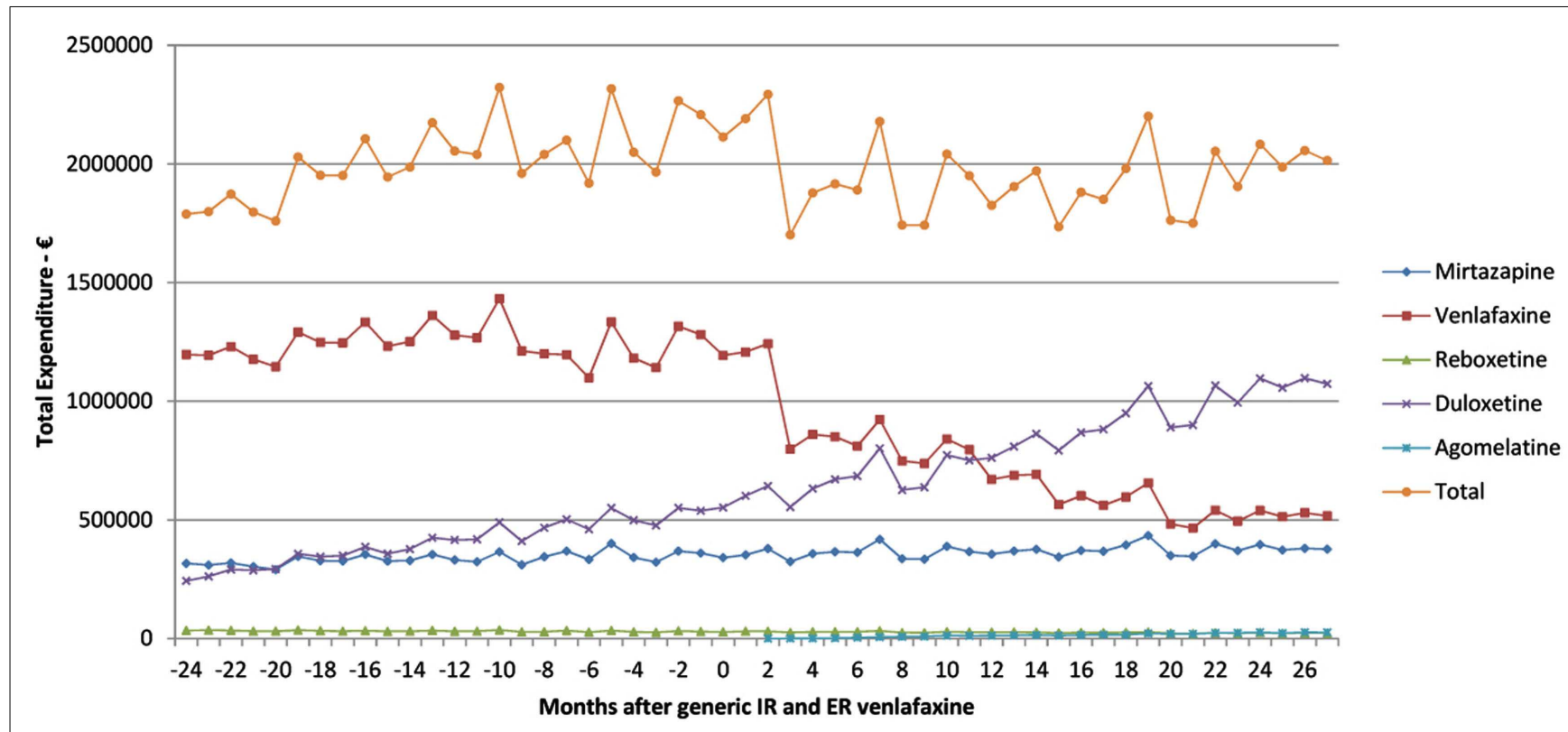

FIGURE 2 | Total expenditure on antidepressants in Austria before and after the availability of generic ER venlafaxine (May 2009).

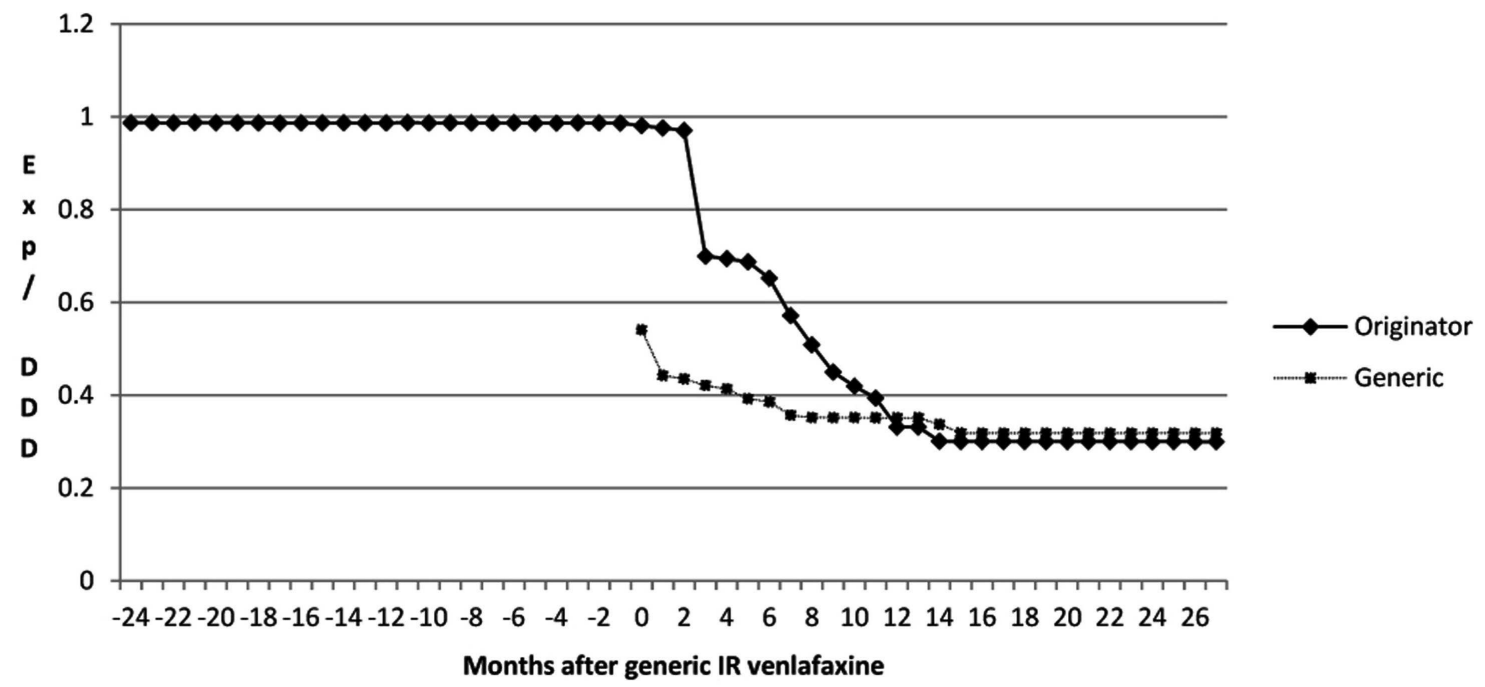

FIGURE 3 | Total expenditure/DDD for venlafaxine IR over time (€).

Specific measures in the case of antidepressants could include academic detailing, prescribing guidance, and prescribing restrictions to encourage the prescribing of multiple-sourced antidepressants such as venlafaxine and mirtazapine where appropriate. Prescribing restrictions have been successfully introduced in Austria to limit the prescribing of atorvastatin and rosuvastatin versus generic statins, ARBs versus ACEIs, and singlesourced ARBs versus generic losartan (Godman et al., 2009c, 2010c, 2012b; Voncina et al., 2011; Bucsics et al., 2012). They have also successfully been instigated in other countries, although care is needed with follow-up to avoid disappointment (Godman et al., 2011b, 2012b).
Prescribing restrictions are an option for duloxetine (Figure 1) given its appreciably higher acquisition costs than multiple-sourced venlafaxine combined with published studies demonstrating lower effectiveness than other antidepressants (Cipriani et al., 2009). The restrictions would limit the prescribing of duloxetine to second line after mirtazapine or venlafaxine if there are concerns with their side-effects or effectiveness in practice. In addition intolerance to either mirtazapine or venlafaxine, which mirrors the situation for ARBs versus ACEIs in Austria (Godman et al., 2010c). We accept that the heterogeneous nature of the therapeutic indications for duloxetine, including diabetic peripheral neuropathic pain, may explain some of its increased 


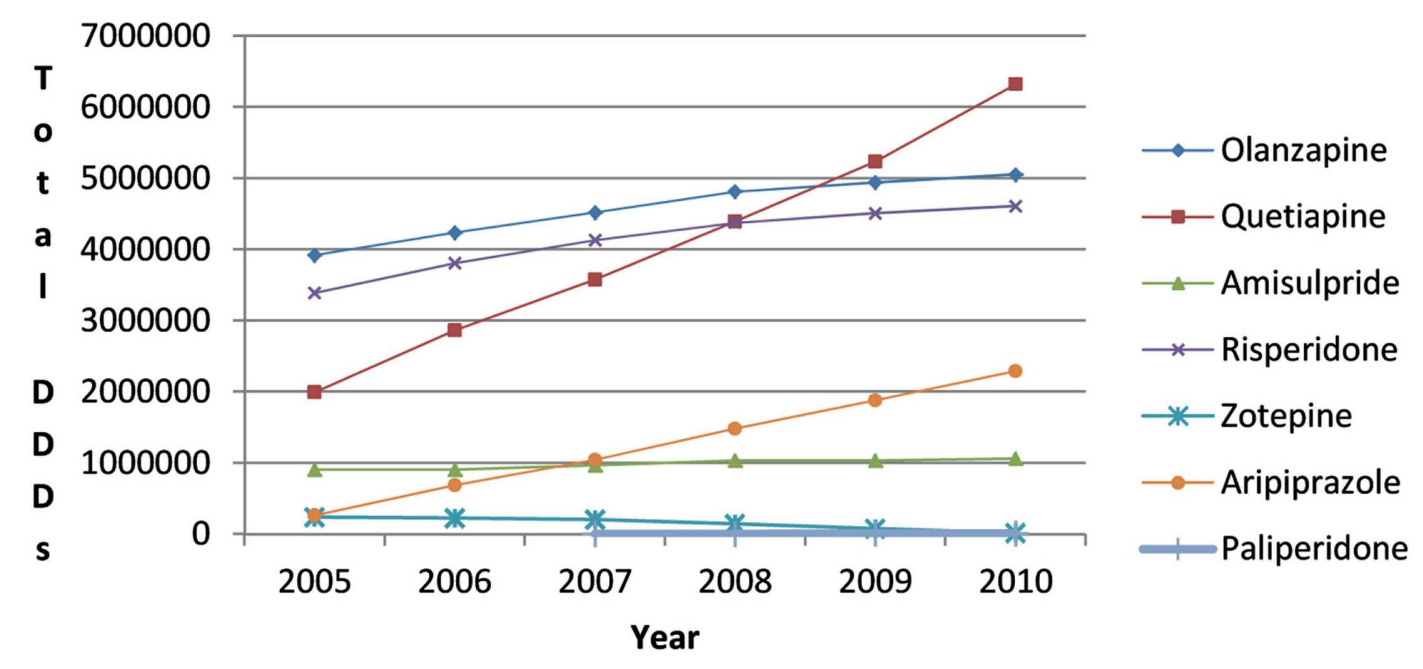

FIGURE 4 | Utilization of atypical antipsychotic drugs in Austria 2005-2010 (DDDs).

utilization in recent years (Figure 1). However, it is difficult to know the extent of prescribing in these other indications without access to specific patient data. Prescribing restrictions have already been introduced for duloxetine in Sweden in similar circumstances [Cymbalta (duloxetine) receives restricted reimbursement, 2010]. As a result, providing an example for the authorities in Austria to follow if wished.

The reduction in expenditure/DDD for IR venlafaxine over time for both generics and the originator (Figure 3 ) is in line with expectations. This reduction mirrors the $83 \%$ reduction in expenditure/DDD for generic losartan in Austria by August 2011 versus single-source prices, generic ACEIs up to $77 \%$ below single-source prices, generic omeprazole $77 \%$ below, and generic simvastatin $72 \%$ below single-source prices by the end of 2007 in Austria (Godman et al., 2009c, 2010c). The reduction in expenditure/DDD for venlafaxine following the availability of multiple-sourced products helped the authorities reduce their expenditure on newer antidepressants in recent years. This was despite their utilization increasing by $37 \%$ from the availability of generic IR and ER venlafaxine to the end of the study (accumulated six monthly basis-Table 1). However, the reduction in total expenditure would have been greater without increasing expenditure on duloxetine in recent months (Figure 2).

There was no appreciable change in the utilization pattern for risperidone following the availability of generic risperidone (Figure 4). This is similar to the situation in Belgium, Scotland, Spain, and Ireland with again no appreciable change in the utilization of risperidone following the availability of generic risperidone (Godman et al., 2012d). This may reflect the advice from organizations such as NICE in the UK, as well as the conclusions from the various Cochrane reviews and the CATIE studies, that treatment with atypical antipsychotics should be tailored to the individual (Walley, 2004; Lieberman et al., 2005; Lieberman and Stroup, 2011; NICE, 2009; Komossa et al., 2010, 2011). Again this is unlike the situation with the PPIs, statins or renin-angiotensin inhibitor drugs, with schizophrenia and bipolar diseases seen as more complex to treat than acid-related stomach disorders, hypercholesterolemia or hypertension. Consequently, again no Hawthorne effect transferring initiatives from other disease areas to schizophrenia or bipolar disease (Holden, 2001; Verstappen et al., 2004; Trietsch et al., 2009; Konstantinou, 2012). The lack of a Hawthorne effect is no doubt enhanced in this situation by lack of any desire among physicians to switch patients between atypical antipsychotic drugs when they are stable on a particular one. As a result, specific measures will be needed to encourage the prescribing of multiple sourced antipsychotic drugs when several options are available to physicians to slow down the growth in the utilisation of single-source atypical antipsychotic drugs (Figure 4). Specific demand-side measures could include new guidelines highlighting the preferential prescribing of generic atypical antipsychotic drugs first line if there are no major patient issues or prescribing restrictions. However, no additional measures are currently being planned by the HVB with both quetiapine and olanzapine now available as multiple-sourced products in Austria. This may change though with increasing recognition that there can be limited clinical benefit of atypical antipsychotic drugs in some patients, alongside potentially life-threatening events (Titier et al., 2005; Maher et al., 2011), and with the possibility of new atypical antipsychotic drugs in the future. However, this remains to be seen.

Finally, there appears to be no problems in practice with either multiple-sourced venlafaxine (IR and ER) or oral risperidone. However, specific research will be needed before we can make any definitive statements.

In conclusion, depression, schizophrenia and bipolar diseases are complex diseases to treat with physicians having no wish to switch patients between medicines, especially when patients are stable on a particular medicine. As a result, specific measures are needed to encourage the prescribing of multiplesourced antidepressants or atypical antipsychotic drugs when several options are available and appropriate, and authorities cannot rely on a "Hawthorne" effect between classes. Specific measures may include guidelines or prescribing restrictions for duloxetine, especially given concerns with its effectiveness versus other newer antidepressants such as venlafaxine and appreciably 
higher acquisition costs. No specific measures are currently being planned for generic atypical antipsychotic drugs in Austria with more multiple-sourced choices becoming available. However, the situation will be monitored.

\section{REFERENCES}

Agüera-Ortiz, L., and Ramos Garcia, I. (2006). Effectiveness of venlafaxine extended release and conventional antidepressants in elderly patients with depressive disorder. Actas Esp. Psiquiatr. 34, 153-161.

Alessi-Severini, S., Honcharik, P. L., Simpson, K. D., Eleff, M. K., and Collins, D. M. (2006). Evaluation of an interchangeability switch in patients treated with clozapine: a retrospective review. J. Clin. Psychiatry 67, 1047-1054.

Alexander, G. C., Gallagher, S. A., Mascola, A., Moloney, R. M., and Stafford, R. S. (2011). Increasing off-label use of antipsychotic medications in the United States, 1995-2008. Pharmacoepidemiol. Drug Saf. 20, 177-184.

Andretta, M., Ciuna, A., Corbari, L., Cipriani, A., and Barbui, C. (2005). Impact of regulatory changes on first- and second-generation antipsychotic drug consumption and expenditure in Italy. Soc. Psychiatry Psychiatr. Epidemiol. 40, 72-77.

Araszkiewicz, A. A., Szabert, K., Godman, B., Wladysiuk, M., Barbui, C., and Haycox, A. (2008). Generic olanzapine: health authority opportunity or nightmare? Expert. Rev. Pharmacoecon. Outcomes Res. 8, 549-555.

Asenjo Lobos, C., Komossa, K., Rummel-Kluge, C., Hunger, H., Schmid, F., Schwarz, S., et al. (2010). Clozapine versus other atypical antipsychotics for schizophrenia. Cochrane Database Syst. Rev. CD006633.

Baldomero, E. B., Ubago, J. G., Cercós, C. L. Ruiloba, J. V., Calvo, C. G., and López, R. P. (2005). Venlafaxine extended release versus conventional antidepressants in the remission of depressive disorders after previous antidepressant failure: ARGOS study. Depress. Anxiety 22, 68-76.

Bazire, S., and Burton, V. (2004). Generic clozapine in schizophrenia: what is all the fuss about? Pharm. J. 173, 720-721.

Bennie, M., Godman, B., Bishop, I., and Campbell, S. (2012). Multiple initiatives continue to enhance the prescribing efficiency for the proton pump inhibitors and statins in Scotland. Expert. Rev. Pharmacoecon. Outcomes Res. 12, 125-130. J. J., and Docherty, J. P. (2012). The impact of the Clinical Antipsychotic Trials of Intervention Effectiveness (CATIE) on prescribing practices: an analysis of data from a large midwestern state. J. Clin. Psychiatry 73, 498-503.

Brkicic, L., Voncina, L., Sovic, S., Godman, B., and Relja, M. (2012). Initiatives to improve prescribing efficiency for drugs to treat Parkinson's Disease in Croatia; influence and future directions. Expert. Rev. Pharmacoecon. Outcomes Res. 12, 373-384.

Bucsics, A., Godman, B., Burkhardt, T., Schmitzer, M., and Malmström, R. E. (2012). Influence of lifting prescribsequent sartan utilization patterns in Austria: implications for other countries. Expert Rev. Pharmacoecon Outcomes Res. 12, 809-819.

Cipriani, A., Furukawa, T. A., Salanti, G., Geddes, J. R., Higgins, J. P., Churchill, R., et al. (2009). Comparative efficacy and acceptability of 12 new-generation antidepressants: a multiple-treatments meta-analysis. Lancet 373, 746-758.

Coma, A., Zara, C., Godman, B., Augusti, A., Diogene, E., Wettermark, B., et al. (2009). Policies to enhance the efficiency of prescribing in the Spanish Catalan Region: impact and future direction. Expert. Rev. Pharmacoecon. Outcomes Res. 9, 569-581.

Correl, C., and Carbon, M. (2012). Brand vs. generic psychotropic medication. Is one better than the other? Available at: https://www.nwpmd. com/LinkClick.aspx?fileticket= vr6K7kfBUfc\%3D\&tabid=342

Crystal, S., Olfson, M., Huang, C., Pincus, H., and Gerhard, T. (2009). Broadened use of atypical antipsychotics: safety, effectiveness, and policy challenges. Health Aff. (Millwood) 28, 770-781.

Cymbalta (duloxetine) receives restricted reimbursement. (2010). TLV Decision Duloxetine, Sweden. Available at: http://www.tlv.se/ Upload/Genomgangen/100615tlv-interim-decision-cymbalta.pdf [accessed October 1, 2012]
Berkowitz, R. L., Patel, U., Ni, Q., Parks, ing restrictions for losartan on sub-

\section{ACKNOWLEDGMENTS}

This work was in part supported by grants from the Karolinska Institutet, Sweden. No writing assistance was provided for this paper.

Department of Justice settlement agreement. (2010). Available at: http://www.justice.gov/usao/ pae/Pharma-Device/astrazeneca settlementagreement.pdf [accessed September 18, 2012]

Desmarais, J. E., Beauclair, L., and Margolese, H. C. (2011). Switching from brand-name to generic psychotropic medications: a literature review. CNS Neurosci. Ther. 17, 750-760.

Fisk, M., Feeley, J., and Voreacos, D. (2012). Je rJ Said to Agree to \$2.2 Billion Drug Marketing Accord. Available at: http://www.businessweek.com/news/ 2012-06-11/j-and-j-said-to-pay-2dot-2-billion-to-end-risperdalsales-probe [accessed November 18, 2012]

Garattini, S., Bertele, V., Godman, B., Haycox, A., Wettermark, B., and Gustafsson, L. L. (2008). Enhancing the rational use of new medicines across European healthcare systems - a position paper. Eur. J. Clin. Pharmacol. 64, 1137-1138.

Gardner, D., Baldessarini, R. J., and Waraich, P. (2005). Modern antipsychotic drugs: a critical overview. CMAJ 172, 1703-1711.

Garuoliene, K., Godman, B., Gulbinovic, J., Wettermark, B., and Haycox, A. (2011). European countries with small populations can obtain low prices for drugs: Lithuania as a case history. Expert. Rev. Pharmacoecon. Outcomes Res. 11, 343-349.

Godman, B., Bucsics, A., Burkhardt, T., Haycox, A., Seyfried, H., and Wieninger, P. (2008a). Insight into recent reforms and initiatives in Austria; implications for key stakeholders. Expert. Rev. Pharmacoecon. Outcomes Res. 8, 357-371.

Godman, B., Haycox, A., Schwabe, U., Joppi, R., and Garattini, S. (2008b). Having your cake and eating it: office of fair trading proposal for funding new drugs to benefit patients and innovative companies. Pharmacoeconomics 26, 91-98.

Godman, B., Wettermark, B., Hoffman, M., Andersson, K., Haycox, A., and Gustafsson, L. L. (2009a). Multifaceted national and regional drug reforms and initiatives in ambulatory care in Sweden; global relevance. Expert. Rev. Pharmacoecon. Outcomes Res. 9, 65-83.

Godman, B., Schwabe, U., Selke, G., and Wettermark, B. (2009b). Update of recent reforms in Germany to enhance the quality and efficiency of prescribing of proton pump inhibitors and lipid lowering drugs. Pharmacoeconomics 27, 435-438.

Godman, B., Burkhardt, T., Bucsics, A., Wettermark, B., and Wieninger, P. (2009c). Impact of recent reforms in Austria on utilisation and expenditure of PPIs and lipid lowering drugs; implications for the future. Expert. Rev. Pharmacoecon. Outcomes Res. 9, 475-484.

Godman, B., Shrank, W., Wettermark, B., Andersen, M., Bishop, I., Burkhardt, T., et al. (2010a). Use of generics - a critical cost containment measure for all healthcare professionals in Europe? Pharmaceuticals 3, 2470-2494.

Godman, B., Shrank, W., Andersen, M., Berg, C., Bishop, I., Burkhardt T., et al. (2010b). Comparing policies to enhance prescribing efficiency in Europe through increasing generic utilisation: changes seen and global implications. Expert. Rev. Pharmacoecon. Outcomes Res. 10, 707-722.

Godman, B., Bucsics, A., Burkhardt, T., Schmitzer, M., Wettermark, B., and Wieninger, P. (2010c). Initiatives to enhance renin-angiotensin prescribing efficiency in Austria; impact and implications for other countries. Expert. Rev. Pharmacoecon. Outcomes Res. 10, 199-207.

Godman, B., Shrank, W., Andersen, M., Berg, C., Bishop, I., Burkhardt, T., et al. (2011a). Policies to enhance prescribing efficiency in Europe: findings and future implications. Front. Pharmacol. 1:141. doi:10.3389/fphar.2010.00141

Godman, B., Sakshaug, S., Berg, C., Wettermark, B., and Haycox, A. (2011b). Combination of prescribing restrictions and policies to engineer low prices to reduce reimbursement costs. Expert. Rev. Pharmacoecon. Outcomes Res. 11, 121-129.

Godman, B., Wettermark, B., Bishop, I., Burkhardt, T., Fürst, J., Garuoliene, K., et al., (2012a). European payer initiatives to reduce prescribing costs through use of generics. GaBi J. 1 , 22-27. 
Godman, B., Malmstrom, R. E., Bennie, M., Sakshaug, S., Burkhardt, T., Campbell, S., et al. (2012b). Prescribing restrictions - a necessary strategy among some European countries to enhance future prescribing efficiency? Rev. Health Care 3, 5-16.

Godman, B., Abuelkhair, M., Vitry, A., Abdu, S., Bennie, M., Bishop, I., et al. (2012c). Payers endorse generics to enhance prescribing efficiency; impact and future implications, a case history approach. GaBi J. 1, 21-35.

Godman, B., Bennett, K., Bennie, M., Burkhardt, T., Schmitzer, M., Martin, A., et al. (2012d). Are health authorities and health insurance companies taking full advantage of the availability of generic risperidone; implications for the future? Pharmacoepidemiol. Drug Saf. 21(Suppl. 3), 55-56.

Grimshaw, J., Campbell, M., Eccles, M., and Steen, N. (2000). Experimental and quasi-experimental designs for evaluating guideline implementation strategies. Fam. Pract. 17(Suppl. 1), S11-S16.

Gustafsson, L. L., Wettermark, B., Godman, B., Andersén-Karlsson, E., Bergman, U., Hasselström, J., et al. (2011). The "Wise List" - a comprehensive concept to select, communicate and achieve adherence to recommendations of essential drugs in ambulatory care in Stockholm. Basic Clin. Pharmacol. Toxicol. 108, 224-233.

Haddad, P. M., and Sharma, S. G. (2007). Adverse effects of atypical antipsychotics: differential risk and clinical implications. CNS Drugs 21, 911-936.

Hargreaves, W. A., and Gibson, J. P. (2005). Effectiveness and cost of risperidone and olanzapine for schizophrenia: a systematic review. CNS Drugs 19, 393-410.

Healy, D. J., Taylor, S., Goldman, M., Barry, K., Blow, F., and Milner, K. K. (2005). Clinical equivalence of generic clozapine. Community Ment. Health J. 41, 393-398.

Heres, S., Davis, J., Maino, K., Jetzinger, E., Kissling, W., and Leucht, S. (2006). Why olanzapine beats risperidone, risperidone beats quetiapine, and quetiapine beats olanzapine: an exploratory analysis of head-to-head comparison studies of second-generation antipsychotics. Am. J. Psychiatry 163, 185-194.

Holden, J. (2001). Hawthorne effects and research into clinical practice. $J$. Eval. Clin. Pract. 7, 65-70.
Khorana, N., Maphanta, S., Lohitnavy, O., Srichaiya, A., and Sayasathid, J. (2011). Comparative pharmacokinetics and bioequivalence of two tablet formulations of $2 \mathrm{mg}$ risperidone in healthy Thai male volunteers. Int. J. Clin. Pharmacol. Ther. 49, 409-414.

Kishimoto, T., Agarwal, V., Kishi, T., Leucht, S., Kane, J. M., and Correll, C. U. (2011). Relapse prevention in schizophrenia: a systematic review and meta-analysis of second-generation antipsychotics versus first-generation antipsychotics. Mol Psychiatry doi:10.1038/mp.2011.143. [Epub ahead of print].

Knapp, M., Kanavos, P., King, D., and Yesudian, H. M. (2005). Economic issues in access to medications: schizophrenia treatment in England. Int. J. Law Psychiatry 28, 514-531.

Komossa, K., Rummel-Kluge, C., Hunger, H., Schmid, F., Schwarz, S., Duggan, L., et al. (2010). Olanzapine versus other atypical antipsychotics for schizophrenia. Cochrane Database Syst. Rev. CD006654. doi:10.1002/14651858.CD006654. pub2.

Komossa, K., Rummel-Kluge, C., Schwarz, S., Schmid, F., Hunger, H., Kissling, W., et al. (2011). Risperidone versus other atypical antipsychotics for schizophrenia. Cochrane Database Syst. Rev. CD006626. doi:10.1002/14651858.CD006626. pub2.

Konstantinou, G. (2012). Pragmatic trials: how to adjust for the 'Hawthorne effect'? Thorax 67, 562.

Leslie, D., and Rosenheck, R. (2012). Off-label use of antipsychotic medications in Medicaid. Am. J. Manag. Care 18, e109-e117.

Leucht, S., Corvers, C., Arbter, D., Engel, R. R., Li, C., and Davis, J. M. (2009). Second-generation versus first-generation antipsychotic drugs for schizophrenia: a meta-analysis. Lancet 373, 31-41.

Leucht, S., Heres, S., Kissling, W., and Davis, J. M. (2011). Evidence-based pharmacotherapy of schizophrenia. Int. J. Neuropsychopharmacol. 14, 269-284.

Leucht, S., Wahlbeck, K., Hamann, J., and Kissling, W. (2003). New generation antipsychotics versus low-potency conventional antipsychotics: a systematic review and meta-analysis. Lancet 361, 1581-1589.

Lieberman, J. A., and Stroup, T. (2011). Commentary - the NIM H-CAT IE schizophrenia study: what did we learn? Am. J. Psychiatry 168, 770-775.

Lieberman, J. A., Stroup, T. S., McEvoy, J. P., Swartz, M. S., Rosenheck, R. A., Perkins, D. O., et al. (2005). Effectiveness of antipsychotic drugs in patients with chronic schizophrenia. N. Engl. J. Med. 353 1209-1223.

Magnus, A., Carr, V., Mihalopoulos, C. Carter, R., and Vos, T. (2005). Assessing cost-effectiveness of drug interventions for schizophrenia. Aust. $N$. Z. J. Psychiatry 39, 44-54.

Maher, A. R., Maglione, M., Bagley, S., Suttorp, M., Hu, J. H., Ewing, B., et al. (2011). Efficacy and comparative effectiveness of atypical antipsychotic medications for offlabel uses in adults: a systematic review and meta-analysis. JAMA 306, 1359-1369.

Martikainen, J., Saastamoinen, L., Korhonen, M., Enlund, H., and Helin-Salmivaara, A. (2010). Impact of restricted reimbursement on the use of statins in Finland: a register-based study. Med. Care 48, 761-766.

McGinn, D., Godman, B., Lonsdale, J., Way, R., Wettermark, B., and Haycox, A. (2010). Initiatives to enhance the quality and efficiency of statin and PPI prescribing in the UK; impact and implications. Expert. Rev. Pharmacoecon. Outcomes Res. 10, 73-85.

Meyer-Massetti, C., Vaerini, S., Rätz Bravo, A. E., Meier, C. R., and Guglielmo, B. J. (2011) Comparative safety of antipsychotics in the WHO pharmacovigilance database: the haloperidol case. Int. J. Clin. Pharm. 33, 806-814.

Mirandola, M., Andretta, M., Corbari, L., Sorio, A., Nosè, M., and Barbui, C. (2006). Prevalence, incidence and persistence of antipsychotic drug prescribing in the Italian general population: retrospective database analysis, 1999-2002. Pharmacoepidemiol. Drug Saf. 15, 412-420.

Mond, J., Morice, R., Owen, C., and Korten, A. (2003). Use of antipsychotic medications in Australia between July 1995 and December 2001. Aust. N. Z. J. Psychiatry 37, 55-61.

NICE. (2009). Schizophrenia - Core interventions in the Treatment and Management of Schizophrenia in Adults in Primary and Secondary Care. NICE Clinical Guideline No. 82. Available at: http://www.nice.org.uk/nicemedia/ live/11786/43610/43610.pdf

NICE. (2008). NICE Implementation Uptake Report: Atypical Antipsychotic Drugs for the Treatment of Schizophrenia. NICE Technology appraisals 43. Available at: http://www.nice.org.uk/media/410/ E9/ImplUptakeReportAtypicalAnti psychotics.pdf

Norman, C., Zarrinkoub, R., Hasselström, J., Godman, B., Granath, F., and Wettermark, B. (2009). Potential savings without compromising the quality of care. Int. J. Clin. Pract. 63, 1320-1326.

Parsons, H. M. (1974). What happened at Hawthorne?: New evidence suggests the Hawthorne effect resulted from operant reinforcement contingencies. Science 183, 922-932.

Paton, C. (2006). Generic clozapine: outcomes after switching. Br. J. Psychiatry 89, 184-185.

Poluzzi, E., Raschi, E., Moretti, U., and De Ponti, F. (2009). Druginduced torsades de pointes: data mining of the public version of the FDA Adverse Event Reporting System (AERS). Pharmacoepidemiol. Drug Saf. 18, 512-518.

R Core Team. (2012). R: A Language and Environment for Statistical Computing. Vienna, Austria: R Foundation for Statistical Computing. Available at: http://www.R-project. org/ [accessed June 30, 2012]

Raja, M. (2011). Clozapine safety, 35 years later. Curr. Drug Saf. 6, 164-184.

Ray, W. A., Chung, C. P., Murray, K. T., Hall, K., and Stein, C. M. (2009). Atypical antipsychotic drugs and the risk of sudden cardiac death. N. Engl. J. Med. 360, 225-235.

Ren, X. S., Qian, S., Lee, A. F., Herz, L., Miller, D. R., and Kazis, L. E. (2006). Treatment persistence: a comparison among patients with schizophrenia who were initiated on atypical antipsychotic agents. J. Clin. Pharm. Ther. 31, 57-65.

Sermet, C., Andrieu, V., Godman, B. Van Ganse, E., Haycox, A., and Reynier, J. P. (2010). Ongoing pharmaceutical reforms in France; implications for key stakeholder groups. Appl. Health Econ. Health Policy 8, 7-24

Spiegel, W., Mlczoch-Czerny, M. T., Jens, R., and Dowrick, C. (2012). Quality circles for pharmacotherapy to modify general practitioners' prescribing behaviour for generic drugs. J. Eval. Clin. Pract. 18, 828-834.

Taylor, D. M., Wright, T., and Libretto, S. (2003). Risperidone compared with olanzapine in a naturalistic clinical study: a cost analysis. J. Clin. Psychiatry 64, 589-597.

Tiihonen, J., Lönnqvist, J., Wahlbeck, W., Klaukka, T., Niskanen, L., 
Tanskanen, A., et al. (2009). 11-year follow-up of mortality in patients with schizophrenia: a populationbased cohort study (FIN11 study). Lancet 374, 620-627.

Titier, K., Girodet, P. O., Verdoux, H., Molimard, M., Bégaud, B., and Haverkamp, W. (2005). Atypical antipsychotics: from potassium channels to torsade de pointes and sudden death. Drug Saf. 28, 35-51.

Trietsch, J., van der Weijden, T., Verstappen, W., Janknegt, R., Muijrers, P., Winkens, R., et al. (2009). A cluster randomized controlled trial aimed at implementation of local quality improvement collaboratives to improve prescribing and test ordering performance of general practitioners: study protocol. Implement. Sci. 4:6. doi:10.1186/17485908-4-6.

Tyrer, P., and Kendall, T. (2009). The spurious advance of antipsychotic drug therapy. Lancet 373, 4-5.

Valenstein, M., Blow, F. C., Copeland, L. A., McCarthy, J. F., Zeber, J. E., Gillon, L., et al. (2004). Poor antipsychotic adherence among patients with schizophrenia: medication and patient factors. Schizophr. Bull. 30, 255-264.

Verstappen, W. H. J. M., van der Weijden, T., ter Riet, G., Grimshaw, J., Winkens, R., and Grol, R. (2004). Block design allowed for control of the Hawthorne effect in a randomized controlled trial of test ordering. J. Clin. Epidemiol. 57, 1119-1123.

Vieweg, W. V., Wood, M. A., and Fernandez, A. (2009). Proarrhythmic risk with antipsychotic and antidepressant drugs: implications in the elderly. Drugs Aging 26, 997-1012.

Vlahovic-Palcevski, V., Gantumur, M., Radosevic, N., Palcevski, G., and Vander Stichele, R. (2010). Coping with changes in Defined Daily Dose in longitudinal drug consumption databases. Pharm. World Sci. 32, 125-129.

Vogler, S., Zimmermann, N., Leopold, C., and de Joncheere, K. (2011). Pharmaceutical policies in European countries in response to the global financial crisis. South. Med. Rev. 4, 22-32.

Voncina, L., Strizrep, T., Godman, B., Bennie, M., Bishop, I., Campbell, S., et al. (2011). Influence of demand side measures to enhance reninangiotensin prescribing efficiency in Europe; implications for the future. Expert. Rev. Pharmacoecon. Outcomes Res. 11, 469-479.

Wagner, A. K., Soumerai, S. B., Zhang, F., and Ross-Degnan, D. (2002). Segmented regression analysis of interrupted time series studies in medication use research. J. Clin. Pharm. Ther. 27, 299-309.

Walley, T. (2004). Neuropsychotherapeutics in the UK. What has been the impact of NICE on prescribing? CNS Drugs 18, 1-12.

Wettermark, B., Godman, B., Andersson, K., Gustafsson, L. L., Haycox, A., and Bertele, V. (2008). Recent national and regional drug reforms in Sweden - implications for pharmaceutical companies in
Europe. Pharmacoeconomics 26 537-550.

Wettermark, B., Pehrsson, A., JuhaszHaverinen, M., Veg, A., Edlert, M., Törnwall-Bergendahl, G., et al. (2009). Financial incentives linked to self-assessment of prescribing patterns - a new approach for quality improvement of drug prescribing in primary care. Qual. Prim. Care 17, 179-189.

Wladysiuk, M., Araszkiewicz, A., Godman, B., Szabert, K., Barbui, C. and Haycox, A. (2011). Patient co-payments do influence atypical antipsychotic choice in Poland; implications once generic atypicals are available. Appl. Health Econ. Health Policy 9, 101-110.

World Health Organization (WHO). (2003). Guidelines for ATC Classification and DDD Assignment 2009. Oslo: WHO Collaborating Centre for Drug Statistics Methodology. Available at: http://www.whocc.no [accessed March 5, 2012]

World Health Organization (WHO). (2012) Introduction to Drug Utilisation Research. WHO International Working Group for Drug Statistics Methodology, WHO Collaborating Centre for Drug Statistics Methodology, WHO Collaborating Centre for Drug Utilization Research and Clinical Pharmacological Services. (NLM classification: WB 330). Available at: http://www.who.int/medicines/ areas/quality_safety/safety_efficacy/ Drug\%20utilization\%20research. pdf [accessed July 3, 2012]

Yu-Isenberg, K. S., Fontes, C. L., Wan, G. J., Geissler, E. C., and Harada,
A. S. (2004). Acute and continuation treatment adequacy with venlafaxine extended release compared with fluoxetine. Pharmacotherapy 24, 33-40.

Conflict of Interest Statement: Anna Bucsics, Thomas Burkhardt, Jutta Piessnegger, and Manuela Schmitzer are employed by the HVB in Austria. The authors have no other conflicts of interest to declare. Thomas Burkhardt has now moved to Wiener Gebietskrankenkasse (WGKK) in Austria.

Received: 28 August 2012; accepted: 06 November 2012; published online: 07 January 2013.

Citation: Godman B, Bucsics A, Burkhardt T, Piessnegger J, Schmitzer $M$, Barbui C, Raschi E, Bennie $M$ and Gustafsson LL (2013) Potential to enhance the prescribing of generic drugs in patients with mental health problems in Austria; implications for the future. Front. Pharmacol. 3:198. doi: 10.3389/fphar.2012.00198

This article was submitted to Frontiers in Pharmaceutical Medicine and Outcomes Research, a specialty of Frontiers in Pharmacology.

Copyright (c) 2013 Godman, Bucsics, Burkhardt, Piessnegger, Schmitzer, Barbui, Raschi, Bennie and Gustafsson. This is an open-access article distributed under the terms of the Creative Commons Attribution License, which permits use, distribution and reproduction in other forums, provided the original authors and source are credited and subject to any copyright notices concerning any third-party graphics etc. 